\title{
Habitar la ciudad líquida ${ }^{1}$
}

Amparo Marroquín Parducci

\section{Introducción}

¿Qué sucede con las ciudades hoy en día, que cambian a cada instante? ¿Cuál es la lógica de estas modernas aglomeraciones de personas que se mueven de un lugar a otro sin apenas tocarse o mirarse, sin llegar nunca a conocerse? Ciudades líquidas las nuestras, creciendo sin uniformarse, expandiéndose con formas caprichosas, adquiriendo figuras donde es imposible precisar un centro. Ciudades líquidas las nuestras, en constante movimiento. En flujo continuo. Con habitantes que se desplazan de un extremo a otro, siguiendo rutinas particulares.

¿Cómo entender este hoy que vivimos si no es a través de su más representativa expresión? La ciudad, sostiene Jesús Barbero, es la metáfora de nuestro tiempo. Es la ciudad de nuestros días la que nos permite visualizar las características cambiantes de esta tardomodernidad que vivimos, como bien explica Giddens (17), al señalar que no hemos aún superado nuestra época moderna y que, al contrario de lo que muchos opinan, estamos en este momento asistiendo a la universalización de "las consecuencias de la modernidad".

¿Cómo explicar y vivir las ciudades de hoy día, estas ciudades que crecen desmesuradamente, superando cualquier pronóstico de los analistas? Jesús Martín Barbero (45) adelanta una pista: "asumir la experiencia de desorden y opacidad que hoy produce ciertamente la ciudad" y enfrentarla con "un pensamiento nómada y plural". Un pensamiento capaz de movilizarse, de hacer enlaces nuevos, un pensamiento que asuma los estallidos que nos están conformando como individuos dentro de estas nuevas urbes.

El presente ensayo utiliza, como insumo principal de reflexión, las pistas que arroja una observación etnográfica de estudiantes universitarios del ITESO de Guadalajara $^{2}$, México; en este sentido, el itinerario que sigo aludirá en muchos 
momentos a la pregunta sobre cómo entender Guadalajara como una ciudad cambiante, una ciudad líquida. Guadalajara es una ciudad grande. Con cinco millones de habitantes y un territorio que ha adjuntado ya otras ciudades cercanas que antes permanecían en las afueras. Con su diversidad y, al mismo tiempo, su identidad particular, permite reflexionar sobre estas ciudades móviles que vivimos en este tiempo.

Además de la observación etnográfica, se retoman dos experiencias personales que ayudan a contrastar y ampliar los datos. La primera es la ciudad de donde procedo, la ciudad de San Salvador, capital de El Salvador, una ciudad de un millón de habitantes, particularmente violenta y hacinada; el único país que supera su cantidad de muertos por violencia es Colombia. Una ciudad improvisada en el sentido más completo del término. Sin historia, sin planificación, sin planos o mapas que permitan orientarse al menos especialmente dentro del territorio. En esa ciudad, los habitantes saben que el sentido de las calles puede cambiar de un día para otro sin previo aviso. Los desastres "naturales" están a la orden del día y cambian la geografía de manera radical, de tal forma que no hay lugares que recordar o paisajes que se anclen en la memoria colectiva para suscitar sensaciones de pertenencia. La segunda experiencia es mi realidad de estar viviendo en Guadalajara, este "ser forastera" al estilo que Alfred Schultz (95) plantea una ventaja en mi manera de aproximarme a la ciudad e intentar re-conocerla. La experiencia de inmersión durante tres meses ha sido bastante provechosa. Tres horas de desplazamiento diario, de esperar en las paradas y compartir la vida dentro de los autobuses le ha dado una perspectiva particular de la ciudad. Dentro de la universidad (ITESO), la situación ha sido similar: la observación de los estudiantes, no sólo en la cafetería y la parada del autobús, sino, sobre todo, en los espacios de uso de las computadoras, ha resultado sumamente enriquecedora. El ensayo retomará en algunos momentos estas dos experiencias que van configurando la manera particular de concebir esta ciudad líquida que es Guadalajara.

\section{La ciudad que fluye: absolutamente sedentarios, completamente móviles}

\section{En la actualidad, todos vivimos en movimiento.}

ZygmunT BaUMAN

Nuestras ciudades llevan a los individuos a una extraña o aparente contradicción en la manera como habitan sus espacios. Hoy día, los ciudadanos son seres completamente móviles, pero al mismo tiempo, absolutamente sedentarios. 


\subsection{Absolutamente sedentarios}

Esta actitud se relaciona con lo que, dentro del paradigma del flujo, Jesús Martín Barbero (60) llama la des-urbanización de las ciudades, que tiene que ver con el hecho de cómo las personas cada vez recorren menos su propia ciudad. Debido a la rapidez, a las constantes amenazas de la violencia - real o aparente-, los individuos crean caminos particulares, itinerarios que recorren una y otra vez sin salirse del mismo paisaje. Sin conocer más que esa mínima parte de su ciudad: de la casa, al trabajo, a la escuela, a la casa del abuelo. Nada más. Sin socializar con extraños, sin desplazarse territorialmente a menos que se vuelva indispensable. $Y$ cuando hay que moverse, se busca un medio de transporte que lleve a la persona de la manera más rápida a otro lugar en el cual se mantendrá de nuevo sedentario. Para qué caminar si se puede usar el camión, para qué usar el camión cuando se puede ir en coche. Los jóvenes son ahora los expertos intérpretes de esta vida sedentaria con desplazamientos físicos mínimos. Son capaces de pasar horas enteras sentados frente al televisor o la computadora. Desde ahí están movilizándose constantemente, de un canal a otro, de un lugar a otro en la red, de un país a otro, pero sin levantarse de su asiento.

Tal pareciera que a mayor expansión territorial de una ciudad, menor se vuelve el espacio que sus habitantes recorren. Guadalajara es una ciudad formada por varias ciudades. Los habitantes suelen escoger el centro comercial más cercano, la escuela más cercana, el templo más cercano (en caso que frecuenten alguno), de tal forma que pueden pasar meses o hasta años sin necesidad de visitar, por ejemplo, el centro histórico de la ciudad.

\subsection{Completamente móviles}

$\mathrm{Y}$ en este aspecto resulta importante detenerse si estamos analizando una ciudad líquida, una ciudad que fluye constantemente. ¿Podemos decir que es esta la nueva manera de habitar la ciudad? En continuo movimiento, sin detenerse, siempre de prisa, sin anclajes.

La vida actual lleva al ciudadano a un cambio infinito. De la casa al trabajo, a las reuniones, al televisor... De los anuncios, a la novela, al noticiero, a la serie... de un canal a otro, en una sucesión infinita donde siempre hay movimiento y nunca anclaje. Se transita siempre, se es, por antonomasia, pasajero. En una ciudad grande, como Guadalajara, no existe El Lugar... esa demarcación territorial que convoca. Hay lugares múltiples. Guadalajara es una ciudad sin un centro, no en el sentido al que se refiere Beatriz Sarlo (13), de una pérdida de valor del centro histórico sustituido por una multitud de shopping centers, sino, en el sentido más literal de la palabra. al estar conformada por varias ciudades, cada una tiene su propio centro. El centro de Zapopan, el centro de Tonalá... cada uno con su plaza, su catedral, su palacio de gobierno. No hay un lugar único para citarse, para encontrarse, Guadalajara posee varios centros históricos.

Habitar la ciudad líquido 
Y cada uno de estos centros, a su vez — y aquí sí retomo el sentido de Sarlo-, proporciona a los habitantes sensaciones de inseguridad. Son lugares demasiado abiertos... ahí puede aparecer el otro, ese rostro desconocido que me devuelve mi imagen, pero de quien no sé nada y de quien — por tanto- puedo esperar lo peor. Guadalajara experimenta, pues, con su crecimiento, otro aspecto fundamental del paradigma del flujo que señala Martín-Barbero (60), el descentramiento. La pérdida de ese espacio fundamental de referencia histórica y su desplazamiento hacia múltiples centros. Es la cita que hace Bauman (104) sobre Pascal: "vivimos en un círculo extraño cuyo centro está en todas partes y su circunferencia en ninguna".

Lo mismo sucede con la universidad. En el ITESO no existe La Cafetería... son varias. Tampoco se puede hablar de El Salón de Cómputo, son cuatro salones permanentes y varios más que se adaptan a las necesidades, dependiendo de la época o de las necesidades del momento. Los horarios para ocupar cada uno varían dependiendo del día y del mes. Tal variedad podría desconcertar en un principio, sin embargo, no hace más que reflejar este des-centramiento de la ciudad. Tal parece que los jóvenes asisten a esta inmersión, no sólo en el descentramiento, sino en la última característica señalada por Martín-Barbero (59): la des-espacialización; en la cual el lugar, el territorio, no cuenta en sí mismo, sino únicamente adquiere valor en la medida que posibilita el flujo, el paso, el movimiento. Tenemos el caso de la cafetería grande de la universidad, la más concurrida de todas, su presentación asemeja la de un pequeño centro comercial. Lugar de tránsito, de consumo, de paso. De un deseo a otro. Espacio en el cual las personas se movilizan y se satisfacen, para continuar movilizándose, en este caso, por el resto del campus. La cafetería así entendida no se vuelve, pues, un espacio de socialización, de encuentro con el otro, el diferente, el que desconozco, sino simplemente un lugar de encuentro con el uno, el semejante, el ya conocido, con el que comparto la experiencia del consumo.

¿De dónde viene esta movilidad? En buena parte de ese deseo consumista que la misma sociedad suscita en los individuos y que Bauman (110) ilustra muy bien al afirmar que somos, en esta época, ante todo viajeros, porque en nuestras ciudades "viajar es esperanza, llegar es una maldición". Este deseo consumista nos lleva a vivir de forma fragmentaria, a consumir de la misma manera y a aprehender, descubrir, conocer con el mismo esquema. La misma cultura de la imagen móvil del videoclip, en la que vivimos inmersos, nos lleva a configurar nuestro entorno fragmentariamente. El zapar (Sarlo, 65) permite al individuo crear su propio discurso itinerante, su propia manera de acercarse al mundo, de vivir la ciudad. Los mismos estudiantes del ITESO hacen estallar los usos tradicionales del espacio y fragmentan sus usos volviéndolos múltiples. La parada donde se espera el camión es lugar de paso, pero, al mismo tiempo, de encuentro. La cafetería es lugar de paso y movilidad, de encuentros breves donde, mientras se come, se hace la tarea, se escucha la canción de la rockola, se 
platica con el compañero las confidencias del día, se fuma rápidamente un cigarro entre una clase y otra. Las computadoras son lugar de paso, donde no hablo con el que está al lado mío, donde transito del trabajo escrito al videojuego, al programa de chat, a la página web, todo en el mismo momento.

"Habitar", sostiene Martin Heidegger (15) "es quedarse, detenerse... Ser ser humano es habitar la tierra, estar..." Este es el sentido primero del término. ¿Mantiene el habitar este sentido en las ciudades móviles de esta modernidad universalizada? Tal parece ser que el sentido es justo el contrario. Habitar no es estar, es moverse, desplazarse. Recorrer territorios. Volverse viajero, en ese placer de la movilidad que narcotiza nuestro cuerpo, tal como lo denomina Richard Sennet (21).

\subsection{Dos formas de habitar, turistas errantes, errantes vagabundos}

Sin embargo, esta movilidad constante de nuestros cuerpos en las ciudades actuales, esta vocación viajera que desarrollamos, no es vivida de la misma manera por todas las personas. Bauman (114) señala dos maneras diferentes de movilidad, de desplazamiento.

Una, la de aquellos que, por su condición socioeconómica pueden acceder a una real determinación de su existencia. Deciden qué hacer y, en este sentido, ingresan a la lógica de la sociedad de consumo de manera voluntaria y consciente. Se vuelven turistas desplazándose a velocidad luz de un lugar a otro, de un con-texto a otro. Para estas personas el espacio no existe, cualquier distancia puede ser recorrida en forma inmediata. Si para Heidegger (17) habitar implicaba una relación hombre-espacio, para los turistas habitar es una relación hombre-tiempo. No sucede así con aquellas personas que se ve forzadas a aceptar una historia, una existencia, un lugar que tal vez no quisieran ocupar pero que les impone y que no tienen más remedio que habitar. Para estos seres, vagabundos errantes que se ven obligados a desplazarse de un lugar a otro, migrantes marginados que ocupan un territorio hasta que son desalojados y se movilizan hasta un nuevo espacio del que también serán movilizados en un círculo eterno, el tiempo no existe, no pasa, no marca nada nuevo; se vuelve un tiempo cíclico y sin sentido y lo que define sus vidas son los distintos espacios por los que forzosamente transitan.

$\mathrm{Y}$ sucede que no solamente hay ciudadanos que transitan estas ciudades móviles como turistas o como vagabundos. Por el contrario, aventuro la posibilidad que en América Latina haya ciudades enteras - líquidas y móviles- que se desplazan de forma vagabunda, sin rumbo, sin sentido, como un San Salvador constantemente cambiando sin planificación prevista, obligado a inventarse después de cada nuevo huracán, de cada terremoto que termina con su infraestructura; o una Guadalajara turista, que conserva su identidad y que es una, pero, al mismo tiempo, múltiple. En San Salvador no hay opciones, hay que moverse a 
cada momento sin optarlo, por urgencia, por mantener la vida, simplemente para continuar... y esta movilidad es la que marca el tiempo que transcurre.

\section{Habitar el flujo: nos-otros y los otros}

...movidos por la pasión de la pertenencia, de amarnos los unos a los unos, con exclusión de los otros...

Michel Serres

En este constante moverse de las ciudades y de aquellos que habitamos las ciudades, nuestras identidades más que conformarse por un anclaje particular se encuentran configuradas desde el desarraigo (Capella, 72).

Si habitamos en constante movimiento el lugar que nos ancla y nos detiene, se vuelve un lugar virtual. El lugar entre, como señala Serres (12), el lugar de paso y tránsito. Como las paradas para esperar el camión. No hay un espacio que sea más transitorio que estas; sin embargo, es el espacio donde se entra en relación entre personas que, de otra manera, no se mirarían jamás a los ojos.

Los lugares de tránsito parecen poner en relación a los semejantes. En la cafetería del ITESO, cada quien con su grupo particular de conocidos, sin rozarse con el otro-distinto-distante; en la parada de los camiones, los vagabundos se encuentran entre sí y juntos comparten el desencanto de tener que recorrer la ciudad de una manera no elegida. Ven pasar desde lejos a los estudiantes-turistas en sus coches, para quienes la ciudad puede tomar la forma que deseen, y que pueden desplazarse a través de la misma siguiendo el itinerario que decidan, el tiempo que escojan para ello.

El reto en estas ciudades líquidas está en buscar la manera de permitir cada vez una mayor capacidad de movilización para todos los habitantes. Y, a nivel macro, la de permitir una real posibilidad de elección sobre su expansión y movilidad a las ciudades de los distintos países.

\section{Bibliografía citada}

Bauman, Zygmunt. La globalización, consecuencias humanas. Buenos Aires: FCE, 1999. Capella, Juan Ramón. Las raices culturales comunitarias. Identidades comunitarias y democracia. Héctor C. Silveira Gorski (ed.). Madrid: Trotta, 2000.

De Certeau, Michel. La invención de lo cotidiano. 1. Artes de hacer. México: Universidad Iberoamericana/ITESO, 1999.

Delgado Ruiz, Manuel. Ciudad líquida, ciudad interrumpida Medellín: Universidad de Antioquia/ Universidad Nacional de Colombia, 1999.

Giddens, Anthony. Consecuencias de la modernidad. Madrid: Alianza, 1994.

Heidegger, Martin. Construir Habitar Pensar. Córdoba: Alción, 1997. 
Martín-Barbero, Jesús. Pensar la ciudad. F. Giraldo, F. Viviescas (comps.). Bogotá: Tercer Mundo, 1996.

Sarlo, Beatriz: Escenas de la vida posmoderna. Intelectuales, arte y videocultura en la Argentina. Buenos Aires: Ariel, 1994.

Schutz, Alfred. El forastero. Ensayo de psicología social, en Estudios sobre teoría social. Buenos Aires: Amorrortu, 1974.

Sennet, Richard. Carne y piedra. El cuerpo y la ciudad en la civilización occidental. Madrid: Alianza, 1997.

Serres, Michel. Atlas. Madrid: Cátedra, 1995.

\section{Notas}

1. El término ciudad líquida ha sido tomado del libro de Manuel Delgado Ruiz, Ciudad líquida, ciudad interrumpida.

2. Cada vez que dentro del documento se hace referencia a "la universidad" o "los universitarios", nos referimos a la observación realizada en el ITESO, universidad jesuita privada, donde asisten estudiantes de distintas clases sociales -aunque la gran mayoría es de clase alta, hay muchos becarios-. 